\title{
Hubungan lingkar lengan atas dengan obesitas pada mahasiswa Fakultas Kedokteran Uuniversitas Sam Ratulangi
}

\author{
1 Okky A. Kumesan \\ ${ }^{2}$ Shane H.R. Ticoalu \\ ${ }^{2}$ Taufiq F. Pasiak
}

\author{
${ }^{1}$ Kandidat Skripsi Fakultas Kedokteran Universitas Sam Ratulangi Manado \\ ${ }^{2}$ Bagian Anatomi Histologi Fakultas Kedokteran Universitas Sam Ratulangi Manado \\ Email: okky.kumesan12301@gmail.com
}

\begin{abstract}
Obesity is defined as abnormal or excessive fat accumulation which detrimental to health. In 2014, more than 1.9 billion adults are overweight and over 600 million of them are obese. Various methods of anthropometry can be used to determine the occurrence of obesity, these methods include measurement of body mass index (BMI), waist circumference, hip circumference, arm circumference and neck circumference, body mass index mostly used as an indicator of obesity to estimate the body fat composition. Based on research conducted by $\mathrm{Lu}$ et al in China, upper arm circumference has been one of the indicators to identify overweight and obesity in children aged 7-12 years. Objective: To determine the relation between upper arms circumference with obesity of students in Faculty of Medicine, Universitas Sam Ratulangi. Method: This research is descriptive analytic observational study conducted in February 2016. The samples were students of the Faculty of Medicine, University of Sam Ratulangi, class 2013, 2014, 2015, who were eligible. The data was obtained by the measurement of upper arm circumference, weight, and height that used in the method of body mass index. Result: The samples in this research were 63 people consisting of 35 men and 28 women with an average age is 19 years old. On BMI measurements obtained an average male's BMI is $29.8 \mathrm{~kg} / \mathrm{m}^{2}$ and women's BMI is 28.6 $\mathrm{kg} / \mathrm{m}^{2}$. On the measurements of upper arm, the average male's upper arm is $33,6 \mathrm{~cm}$ and women's upper arm is $30,7 \mathrm{~cm}$. Spearman correlation values between the Upper Arm Circumference and BMI for the all sample is 0,711. Conclusion: There is strong correlations between the Upper Arm Circumference (MUAC) with obesity that were measured with Body Mass Index (BMI).
\end{abstract}

Keywords: obesity, body mass index, upper arm circumference, student

\begin{abstract}
Abstrak: Obesitas didefinisikan sebagai akumulasi lemak abnormal atau berlebihan yang dapat menggangu kesehatan. Pada tahun 2014, lebih dari 1,9 miliar orang dewasa mengalami kelebihan berat badan dan lebih dari 600 juta orang diantaranya mengalami obesitas. Berbagai macam metode antropometri dapat digunakan untuk mengetahui terjadinya obesitas, metode-metode tersebut antara lain pengukuran indeks masa tubuh (IMT), lingkar pinggang, lingkar pinggul, lingkar lengan, serta lingkar leher, indeks masa tubuh merupakan indikator kegemukan yang banyak dilakukan untuk memperkirakan komposisi lemak tubuh. Berdasarkan penelitian yang dilakukan oleh Lu dkk di Cina, lingkar lengan atas telah merupakan salah satu indikator untuk mengidentifikasi berat badan lebih dan obesitas pada anak-anak usia 7-12 tahun. Penelitian ini bertujuan untuk mengetahui hubungan antara lingkar lengan atas dengan terjadinya obesitas pada mahasiswa Fakultas Kedokteran Universitas Sam Ratulangi. Penelitian ini merupakan jenis penelitian deskriptif observasional analitik yang dilaksanakan pada bulan Februari 2016. Sampel penelitian adalah mahasiswa Fakultas Kedokteran Universitas Sam Ratulangi, angkatan 2013, 2014,
\end{abstract}


2015 yang memenuhi kriteria. Data penelitian didapatkan melalui pengukuran lingkar lengan atas, berat badan, serta tinggi badan yang digunakan dalam metode indeks masa tubuh. Pada penelitian ini didapatkan sampel sebanyak 63 orang yang terdiri dari 35 orang laki-laki dan 28 orang perempuan dengan rata-rata umur sampel 19 tahun. Pada pengukuran IMT didapatkan rata-rata IMT laki-laki $29,8 \mathrm{~kg} / \mathrm{m}^{2}$ dan IMT Perempuan $28,6 \mathrm{~kg} / \mathrm{m}^{2}$. Pada pengukuran LiLA didapatkan rata-rata LiLA laki-laki 33,6 cm dan LiLA perempuan 30,7 $\mathrm{cm}$. Nilai korelasi Spearman antara Lingkar Lengan Atas dan IMT untuk seluruh sampel sebesar 0,711. Simpulan: Didapatkan hubungan yang kuat antara Lingkar Lengan Atas (LiLA) dengan obesitas yang diukur meggunakan Indeks Massa Tubuh (IMT)

Kata kunci: obesitas, indeks masa tubuh, lingkar lengan atas, mahasiwa

Obesitas didefinisikan sebagai akumulasi lemak abnormal atau berlebihan yang dapat menggangu kesehatan. Pada tahun 2014, lebih dari 1,9 miliar orang dewasa mengalami kelebihan berat badan dan lebih dari 600 juta orang diantaranya mengalami obesitas. ${ }^{1}$ Di Indonesia prevalensi obesitas pada tahun 2013 adalah sekitar 19,7\% untuk laki-laki dan $32,9 \%$ untuk perempuan dewasa. Sulawesi Utara menempati prevalensi obesitas tertinggi di Indonesia yaitu laki-laki sebanyak 34,7\% dan perempuan sekitar $48 \%{ }^{2}$

Obesitas merupakan faktor predisposisi untuk terjadinya berbagai macam penyakit degeneratif seperti hipertensi, osteoartritis, penyakit jantung iskemik, gangguan pernapasan, dan diabetes melitus. ${ }^{3}$

Berbagai macam metode antropometri dapat digunakan untuk mengetahui terjadinya obesitas, metode-metode tersebut antara lain pengukuran indeks masa tubuh (IMT), lingkar pinggang, lingkar pinggul, lingkar lengan, serta lingkar leher, indeks masa tubuh merupakan indikator kegemukan yang banyak dilakukan untuk memperkirakan komposisi lemak tubuh. Indeks masa tubuh (IMT) merupakan salah satu indeks antropometri sederhana yang digunakan untuk memantau status gizi orang dewasa 18 tahun ke atas dan berkaitan dengan kekurangan dan kelebihan berat badan. IMT adalah rasio antara berat badan $(\mathrm{kg})$ dan kuadrat tinggi badan $\left(\mathrm{m}^{2}\right){ }^{4}$

Berdasarkan penelitian yang dilakukan oleh Lu dkk ${ }^{5}$ di Cina, lingkar lengan atas telah merupakan salah satu indikator untuk mengidentifikasi berat badan lebih dan obesitas pada anak-anak usia 7-12 tahun. ${ }^{5}$

Pengukuran lingkar lengan atas untuk mengetahui kelompok yang beresiko kekurangan energi kronik atau KEK maupun yang mengalami kelebihan distribusi lemak di bagian lengan pada orang yang mengalami obesitas. Lingkar lengan atas dewasa ini memang merupakan salah satu pilihan untuk menentukan gizi, karena mudah dilakukan dan memerlukan alat-alat yang tidak sulit untuk diperoleh. ${ }^{6}$ Berdasarkan uraian di atas, peneliti tertarik untuk mengetahui hubungan antara lingkar lengan atas dengan terjadinya obesitas pada mahasiswa Fakultas Kedokteran Universitas Sam Ratulangi.

\section{METODE PENELITIAN}

Penelitian ini merupakan jenis penelitian deskriptif observasional analitik. Data penelitian melalui pengukuran lingkar lengan atas, berat badan, serta tinggi badan yang digunakan dalam metode indeks masa tubuh, dengan desain cross sectional. Penelitian dilakukan pada bulan Februari 2016 di Fakultas Kedokteran Universitas Sam Ratulangi dengan subjek penelitian yaitu mahasiswa Fakultas Kedokteran Universitas Sam Ratulangi perempuan maupun laki-laki, angkatan 2013, 2014, 2015 yang memenuhi syarat-syarat berbadan sehat, usia 17-22 tahun, tidak terlatih / tidak mengikuti fitness, dan bersedia ikut serta dalam penelitian. Dilakukan pengukuran lingkar lengan atas dan IMT pada setiap subjek penelitian kemudian dikumpulkan data dan dilakukan analisis data untuk melihat korelasi antara lingkar lengan atas dengan IMT 
menggunakan program komputerisasi SPSS

\section{HASIL PENELITIAN}

Pada penelitian yang dilakukan pada Mahasiswa Fakultas Kedokteran angkatan 2013, 2014 dan 2015 dengan mengukur Indeks Massa Tubuh (IMT) dan Lingkar Lengan Atas (LiLA) didapatkan sampel sebanyak 63 orang yang terdiri dari 35 orang laki-laki dan 28 orang perempuan (Tabel 1).

Tabel 1. Distribusi Sampel Berdasarkan Jenis Kelamin

\begin{tabular}{ccc}
\hline $\begin{array}{c}\text { Jenis } \\
\text { Kelamin }\end{array}$ & $\begin{array}{c}\text { Jumlah } \\
(\mathbf{n})\end{array}$ & $\begin{array}{c}\text { Persentase } \\
(\boldsymbol{\%})\end{array}$ \\
\hline Laki-laki & 35 & $55,56 \%$ \\
\hline Perempuan & 28 & $44,44 \%$ \\
\hline TOTAL & 63 & $100 \%$ \\
\hline
\end{tabular}

Pada Tabel 2 dapat dilihat bahwa rata-rata umur sampel laki-laki dengan kisaran umur 17 - 22 tahun adalah 19 tahun dan pada perempuan dengan kisaran umur 17 - 22 tahun mempunyai rata-rata 19 tahun.

Tabel 2. Karakteristik Umur

\begin{tabular}{cccc}
\hline $\begin{array}{l}\text { Karakteristik } \\
\text { Sampel }\end{array}$ & $\begin{array}{c}\text { Jumlah } \\
\text { Sampel }\end{array}$ & $\begin{array}{c}\text { Min-Maks } \\
\text { (thn) }\end{array}$ & $\begin{array}{c}\text { Rata- } \\
\text { rata }\end{array}$ \\
\hline Laki-laki & 35 & $17-22$ & 19 \\
Perempuan & 28 & $17-22$ & 19 \\
Total Sampel & 63 & $17-22$ & 19 \\
\hline
\end{tabular}

Tabel 3 menunjukkan bahwa tinggi badan sampel laki-laki dengan kisaran $159,9-182 \mathrm{~cm}$ mempunyai rata-rata tinggi badan $169,8 \mathrm{~cm}$ dan pada perempuan dengan kisaran 146 - 173,5 cm didapati rata-rata sebesar $155,8 \mathrm{~cm}$.

Tabel 3. Karakteristik Tinggi Badan

\begin{tabular}{cccc}
\hline $\begin{array}{c}\text { Karateristik } \\
\text { Sampel }\end{array}$ & $\begin{array}{c}\text { Jumlah } \\
\text { Sampel }\end{array}$ & $\begin{array}{c}\text { Min-Maks } \\
(\mathbf{c m})\end{array}$ & $\begin{array}{c}\text { Rata- } \\
\text { rata }\end{array}$ \\
\hline Laki-laki & 35 & $159,9-182$ & 169,8 \\
Perempuan & 28 & $146-173,5$ & 155,8 \\
Total Sampel & 63 & $146-182$ & 163,5 \\
\hline
\end{tabular}

Pada Tabel 4, dapat dilihat bahwa berat badan sampel laki-laki dengan kisaran 69$108 \mathrm{~kg}$ mempunyai rata-rata berat badan $85,5 \mathrm{~kg}$ sedangkan pada perempuan dengan kisaran berat badan 54- $102 \mathrm{~kg}$ mempunyai rata-rata $69,5 \mathrm{~kg}$.

Tabel 4. Karakteristik Berat Badan

\begin{tabular}{cccc}
\hline $\begin{array}{c}\text { Karateristik } \\
\text { Sampel }\end{array}$ & $\begin{array}{c}\text { Jumlah } \\
\text { Sampel }\end{array}$ & $\begin{array}{c}\text { Min-Maks } \\
\text { (kg) }\end{array}$ & $\begin{array}{c}\text { Rata- } \\
\text { rata }\end{array}$ \\
\hline Laki-laki & 35 & $69-108$ & 85,5 \\
Perempuan & 28 & $54-102$ & 69,5 \\
Total & 63 & $54-108$ & 78,6 \\
Sampel & & & \\
\hline
\end{tabular}

Dapat dilihat pada Tabel 5 sampel indeks massa tubuh (IMT) laki-laki dengan kisaran 25,04-37,2 mempunyai rata-rata 29,8 sedangkan pada sampel perempuan dengan kisaran (IMT) 25-37,15 mempunyai rata-rata 28,6 dan total sampel dengan kisaran 25-37,2 mempunyai rata-rata indeks massa tubuh (IMT) 29,2.

Tabel 5. Karakteristik Indeks Massa Tubuh (IMT)

\begin{tabular}{cccc}
\hline $\begin{array}{c}\text { Karateristik } \\
\text { Sampel }\end{array}$ & $\begin{array}{c}\text { Jumlah } \\
\text { Sampel }\end{array}$ & $\begin{array}{c}\text { Min-Maks } \\
\left(\mathbf{k g} / \mathbf{m}^{\mathbf{2}}\right)\end{array}$ & $\begin{array}{c}\text { Rata- } \\
\text { rata }\end{array}$ \\
\hline Laki-laki & 35 & $26-39,5$ & 33,6 \\
Perempuan & 28 & $26-38$ & 30,7 \\
Total Sampel & 63 & $26-39,5$ & 32,3 \\
\hline
\end{tabular}

Pada Tabel 6 dapat dilihat ukuran lingkar lengan atas (LiLA) sampel laki laki dengan kisaran 26-39,5 cm mempunyai ukuran rata-rata $33,6 \mathrm{~cm}$, pada perempuan dengan kisaran 26-38 cm mempunyai rata rata ukuran $30,7 \mathrm{~cm}$ dan pada total sampel dengan kisaran 26-39,5 cm mempunyai rata -rata ukuran lingkar lengan atas (LiLA) sebesar $32,3 \mathrm{~cm}$.

Tabel 6. Karakteristik Lingkar Lengan Atas (LiLA)

\begin{tabular}{cccc}
\hline $\begin{array}{c}\text { Karateristik } \\
\text { Sampel }\end{array}$ & $\begin{array}{c}\text { Jumlah } \\
\text { Sampel }\end{array}$ & Min-Maks & $\begin{array}{c}\text { Rata- } \\
\text { rata }\end{array}$ \\
\hline Laki-laki & 35 & $25,04-37,2$ & 29,8 \\
Perempuan & 28 & $25-37,15$ & 28,6 \\
Total Sampel & 63 & $25-37,2$ & 29,2 \\
\hline
\end{tabular}


Untuk melihat adanya hubungan antara Lingkar Lengan Atas dengan Indeks Massa Tubuh maka digunakan uji korelasi Spearman rho (Tabel 7).

Tabel 7. Hubungan antara Lingkar Lengan Atas dengan Indeks Massa Tubuh menggunakan uji korelasi Spearman rho.

\begin{tabular}{cccc}
\hline & & & IMT \\
\hline Laki-Laki & Lingkar & $\mathrm{R}$ & $0,858^{* *}$ \\
\cline { 4 - 4 } & Lengan & $\mathrm{P}$ & 0,000 \\
\cline { 4 - 4 } \cline { 4 - 4 } Perempuan & Atas & $\mathrm{R}$ & $0,591^{* *}$ \\
\cline { 4 - 4 } & (LiLA) & $\mathrm{P}$ & 0,001 \\
\cline { 3 - 4 } Total & & $\mathrm{R}$ & $0,711^{* *}$ \\
\cline { 3 - 4 } Sampel & & $\mathrm{P}$ & 0,000 \\
\hline
\end{tabular}

Tabel 7 menunjukkan adanya hubungan yang signifikan ( $p<0,005)$. Diketahui bahwa nilai korelasi Spearman pada sampel yang berjenis kelamin lakilaki sebesar 0,858 pada sampel yang berjenis kelamin perempuan 0,591 dan pada keseluruhan sampel sebesar 0,711. Hal ini menunjukkan bahwa adanya hubungan yang kuat antara Lingkar Lengan Atas dengan Indeks Massa Tubuh.

\section{BAHASAN}

Penelitian sebelumnya yang dilakukan Laoh $\mathrm{dkk}^{4}$ pada mahasiswa kedokteran Unsrat yang aktif kuliah pada tahun 2013 didapatkan jumlah keseluruhan mahasiswa yang mengalami obesitas sebanyak 111 orang yang terdiri dari 73 orang laki-laki dan 38 orang perempuan. ${ }^{4}$ Sedangkan pada penelitian ini didapatkan jumlah keseluruhan mahasiswa yang mengalami obesitas sebanyak 63 orang yang terdiri dari 35 orang laki-laki dan 28 orang perempuan.

Obesitas disebabkan oleh ketidakseimbangan antara jumlah energi yang masuk dengan yang dibutuhkan oleh tubuh untuk berbagai fungsi biologis seperti perubahan fisik, perkembangan, aktifitas, dan pemeliharaan kesehatan. ${ }^{7}$

Pada penelitian ini, didapatkan ratarata usia sampel penelitian dari rentang usia $17-22$ tahun adalah 19 tahun. Hal ini tidak sama dengan penelitian sebelumnya yang dilakukan juga pada mahasiswa kedokteran Unsrat yang mengalami obesitas dimana rata-rata usia sampel penelitian dari rentang usia 17-22 tahun adalah 20 tahun. ${ }^{8}$ Perbedaan ini dikarenakan kebanyakan sampel merupakan angkatan baru yang masuk di Fakultas Kedokteran Unsrat yang masih berusia muda.

Data Indeks Massa Tubuh pada penelitian ini mulai dari terendah $25 \mathrm{~kg} / \mathrm{m}^{2}$ sampai yang tertinggi $37,2 \mathrm{~kg} / \mathrm{m}^{2}$ dengan rata-rata $29,23 \quad \mathrm{~kg} / \mathrm{m}^{2}$. Penelitian sebelumnya yang dilakukan pada tahun 2012 didapatkan rata-rata IMT $26,81 \mathrm{~kg} / \mathrm{m}^{2}$ dan pada tahun 2013 rata-rata IMT 29,18 $\mathrm{kg} / \mathrm{m}^{2}{ }^{4,8}$ Terlihat rata-rata IMT terjadi peningkatan dari tahun ke tahun. Pada penelitian yang dilakukan Emelia pada remaja di Amerika menemukan bahwa terdapat kecenderungan remaja menurunkan konsumsi makanan berserat buah dan sayur segar, dan semakin beralih ke buah kaleng dan juz siap saji. ${ }^{9}$ Pada masa remaja mudah terpengaruh oleh teman sebaya lebih besar daripada keluarga, remaja lebih mudah menerima pengaruh globalisasi, pengaruh pola makan Western (Eropa) dengan tinggi asupan lemak namun rendah serat. ${ }^{10}$

Faktor-faktor lain yang menyebabkan perilaku makan tidak baik ialah psikologis, dimana perilaku makan dapat dijadikan sebagai sarana pengalihan stress. Perilaku makan yang tidak baik pada masa kanakkanak sehingga terjadi kelebihan nutrisi juga memiliki kontribusi dalam obesitas, hal ini didasarkan karena kecepatan pembentukan sel-sel lemak yang baru terutama meningkat pada tahun-tahun pertama kehidupan, dan makin besar kecepatan penyimpanan lemak, makin besar pula jumlah sel lemak. Oleh karena itu, obesitas pada kanak-kanak cenderung mengakibatkan obesitas pada dewasanya nanti. Mujianto menemukan 15-20\% remaja Indonesia biasa mengkonsumsi ayam goreng dan burger produk luar negeri. $87 \%$ preremaja dan remaja suka makan diluar, seperti es campur, bakso dan jajanan lainya. Kehadiran fast food dalam industri makanan di Indonesia 
mempengaruhui pola makan. Restoran fast food menjadi tempat yang santai bagi kalangan menengah keatas. ${ }^{11}$

Pada penelitian ini, didapatkan nilai korelasi Spearman sebesar 0,711 yang menunjukan bahwa adanya hubungan yang kuat antara Lingkar Lengan Atas dengan Indeks Massa Tubuh. Hal ini sejalan dengan penelitian yang dilakukan oleh Mazicioğlu dkk ${ }^{23}$ di Turkey tahun 2006 dan Lu dkk ${ }^{5}$ di China tahun 2011 pada rentang umur yang berbeda yaitu 6-17 tahun dan 712 tahun dimana hasil penelitiannya menunjukkan hubungan yang kuat antara LiLA dan IMT. ${ }^{6,12}$

Dari hasil penelitian ini, menunjukan bahwa LiLA memiliki potensi untuk digunakan dalam skrining dari kelebihan gizi, yang memerlukan penelitian lebih lanjut pada populasi dan kategori umur yang lebih beragam.

\section{SIMPULAN}

Pada penelitian yang dilakukan pada 63 mahasiswa fakultas kedokteran Unsrat yang mengalami obesitas didapatkan hubungan yang kuat antara Lingkar Lengan Atas (LiLA) dengan obesitas yang diukur meggunakan Indeks Massa Tubuh (IMT) dengan nilai korelasi Spearman pada sampel yang berjenis kelamin laki-laki sebesar 0,858 pada sampel yang berjenis kelamin perempuan 0,591 dan pada keseluruhan sampel sebesar 0,711 .

\section{SARAN}

Peneliti menyarankan agar hasil penelitian ini dapat dijadikan data dasar atau bahan acuan untuk dilakukan penelitian yang sama dan dalam jumlah sampel yang lebih banyak serta rentang umur dan populasi yang lebih beragam untuk lebih membuktikan penggunaan pengukuran LiLA pada skrining kelebihan status gizi. Selain itu, penelitian dengan menggunakan metode antropometri lain juga disarankan untuk dilakukan.

Dengan mengetahui hasil dari penelitian ini, diharapkan dapat menjadi acuan atau bahan pertimbangan bagi mahasiswa khususnya mahasiswa kedokteran Unsrat sendiri untuk lebih memperhatikan pola makan yang sehat dan teratur untuk mengurangi angka kejadian obesitas.

\section{DAFTAR PUSTAKA}

1. WHO. Obesity and overweight. Januari 2015 [diakses 15 oktober 2015]. Tersedia di: http://www.who.int/mediacentre/facts heets/fs311/en/

2. Badan Penelitian dan Pengembangan Kesehatan Kemenkes RI. Riset Kesehatan Dasar. Jakarta. 2013

3. Hermawan AG. Komplikasi Obesitas dan Usaha Penanggulangannya. Cermin Dunia Kedokteran. 1991; 68:39-41.

4. Laoh VCE, Tanudjaja GN, Ticoalu SHR. Hubungan Lingkar Leher Dengan Obesitas Pada Mahasiswa Fakultas Kedokteran Universitas Sam Ratulangi. [skripsi]. [Manado]: Universitas Sam Ratulangi. 2013

5. Lu Q, Wang R, Lou DH, Ma CM, Liu XL, Yin, FZ. Mid-upper-arm Circumference and Arm-to-height Ratio in Evaluation of Overweight and Obesity in Han Children. Journal Pediatrics and Neonatology. 2014

6. Waspadji S, Saryono S, Sukardji K, Krenawan T. Pengkajian Status Gizi. Balai Penerbit FKUI. Jakarta. 2010;2

7. Imam AA. Manfaat Isoflavon dalam Produk Kedelai Menanggulangi Diabetes serta Mencegah Obesitas dan Osteoporosis [Skripsi]. Makassar: Universitas Hasanuddin; 2013.

8. Yohan HOP, Waleleng BJ, Wantania F. Hubungan Antara Indeks Massa Tubuh dengan Estimasi laju filtrasi glomerulur pada mahasiswa dengan obesitas di Fakultas Kedokteran Universitas Sam Ratulangi Manado. E-clinic. 2014;2(1)

9. Sumarcana. Pengetahuan, sikap dan praktek gizi pada remaja dan implikasinya pada sosialisasi perilaku hidup sehat [Skripsi]. Medan: USU; 2009.

10.Kaprianan MT. Asupan tinggi lemak dan aktifitas olahraga sebagai faktor resiko terjadinya Hipertensi Obesitik pada awal remaja [Skripsi]. Semarang: UNDIP; 2012.

11.Merawati D, Kinanti RG. Perilaku Makan pada Siswa Obesitas. Jurnal Iptek 
Kumesan, Ticoalu, Pasiak: Hubungan lingkar lengan...

Olahraga. 2005;7(3):182-192.

12.Mazicioğlu MM, Hatipoğlu N, Öztürk A, Çiçek B, Üstünbaş HB, Kurtoğlu S. Waist Circumference and Mid-Upper
Arm Circumference in Evaluation of Obesity in Children Aged Between 6 and 17 Years. J Clin Res Ped Endo 2010;2(4):144-150. 